\title{
A randomized controlled trial to compare the effects of liquid versus powdered recombinant human growth hormone in treating patients with severe burns
}

\author{
GUOXIAN CHEN, HUAWEI SHAO and XUANLIANG PAN \\ Department of Burns, Second Affiliated Hospital of Zhejiang University School of Medicine, \\ Hangzhou, Zhejiang 310009, P.R. China
}

Received August 25, 2015; Accepted January 22, 2016

DOI: $10.3892 /$ br.2016.635

\begin{abstract}
Recombinant human growth hormone (rhGH) promotes protein utilization and synthesis, and is widely used as a therapy to treat severe burns. The present randomized controlled trial evaluated the effects of different forms of rhGH on patients with severe burns. A total of 29 adult severe burns patients were enrolled between February 2009 and November 2011, and randomly assigned to either treatment group ( $\mathrm{T}$, liquid $\mathrm{rhGH}$ ) or control group (C, powder rhGH). From days 5 to 7 following the infliction of burns, both patient groups received $\mathrm{rhGH}$ at $0.067 \mathrm{mg} / \mathrm{kg} / \mathrm{d}$, once for 10 days. Median serum pre-albumin levels increased in both groups following treatment, the elevation from baseline was significantly higher in the $\mathrm{T}$ group on day 10 compared to the $\mathrm{C}$ group ( $88 \mathrm{mg} / \mathrm{l}$ vs. $65 \mathrm{mg} / \mathrm{l}, \mathrm{P}=0.046$ ). C-reactive protein, fasting plasma glucose and body weight decreased in both groups. Body weight was significantly lower in the $\mathrm{T}$ compared to the $\mathrm{C}$ group at baseline, Day 5 and Day $10(\mathrm{P}=0.046, \mathrm{P}=0.018$ and $\mathrm{P}=0.006$, respectively), however the decrease from baseline levels were not significantly different. Wound healing time was similar between groups $(\mathrm{P}=0.270)$. In conclusion the early use of liquid rather than powder rhGH may be more beneficial for treating adult patients with severe burns.
\end{abstract}

\section{Introduction}

Severe burns that cover a large total body surface area result in serious risks to the patient in terms of morbidity and mortality, and in most cases should be treated in a specialized burns unit (1). Modern treatments for severe burns include skin replacement therapy using biomaterials or grafts, prevention

Correspondence to: Dr Guoxian Chen, Department of Burns, Second Affiliated Hospital of Zhejiang University School of Medicine, Hangzhou, Zhejiang 310009, P.R. China

E-mail: gxchen66@163.com

Key words: burns, recombinant human growth hormone, pre-albumin, dosage forms, adult metabolism of infection using antibiotics and sterile conditions, treatment of sepsis, and targeted protein therapies $(2,3)$. In addition to the pain and tissue damage caused by severe burns, the process of recovery can cause problems resulting from the high requirement of the body for energy and proteins. Patients with severe burns experience an initial ebb phase over the first two days post-burn, where metabolism decreases. A period of flow occurs during hypermetabolism that can last for many months post-burn (4). This process involves multiple factors; plasma catecholamines, cortisol and inflammatory cells are elevated, leading to whole-body catabolism, elevated resting energy expenditure and multi-organ dysfunction (4). If this process is left unchecked it can prevent a patient's full rehabilitation and delay wound healing (5). Modulation of the response by early treatment, thermoregulation, early and continuous enteral feeding with high protein-high carbohydrate diets and pharmacologic treatments markedly decrease morbidity (4). Pharmacologic treatments include anabolic agents, $\beta$-adrenergic receptor antagonists and anti-hyperglycemic agents (6).

One of the pharmacologic treatments used to treat severe burns involves recombinant human growth hormone (rhGH). Growth hormone $(\mathrm{GH})$ is an important anabolic hormone that has multiple physiological functions. Human GH is composed of 191 amino acid residues and is secreted by the pituitary gland for anabolism, to promote the growth of different tissues. Since the 1950s, purified bovine and human GH has been administered to patients during clinical practice, but these are limited sources of $\mathrm{GH}$, and there have been some concerns about contamination (7). With the emergence of synthetic rhGH produced commercially in bacteria, $\mathrm{GH}$ is now more widely used in clinical therapeutic strategies (7). For children, $\mathrm{GH}$ can be used to provide catch-up growth treatment in children born small for their gestational age (8). At present, $\mathrm{GH}$ is widely used for many different therapies including $\mathrm{GH}$ replacement, severe brain trauma, and wound healing (9-11). Since most severely burned patients have an associated dysfunction in protein synthesis, $\mathrm{rhGH}$ can promote protein utilization and synthesis, and its curative effects have been widely recognized by clinicians. In addition, rhGH has also been recommended in the nutritional supporting guideline for burn patients in China (12), and a recent Cochrane review 
suggested that there was some evidence the rhGH could result in more rapid healing of severe burns (13).

The commercially available forms of rhGH include freeze-dried powders, but recently liquid formulas are available, with similar pharmacokinetic and safety profiles to the powdered form $(14,15)$. A liquid form of rhGH may have advantages in terms of there being no need to reconstitute the powder, and so the risk of dilution or contamination problems may be decreased (14), in addition powdered $\mathrm{rhGH}$ may undergo aggregation during reconstitution resulting in misfolded protein (16). Therefore, liquid rhGH may be more biologically active, faster acting, more convenient to use and more effective (17) than the powdered form. However, few previous studies have compared the clinical effects of both forms of rhGH, and for burn patients, it is unclear which form is most beneficial. We hypothesized that liquid rhGH may be beneficial to patients with severe burns when compared to the powdered form. Thus the aim of the present study was to evaluate the effects of liquid and powder rhGH in improving visceral protein synthesis in severely burned patients, and to provide evidence for the rational use of rhGH in burns patients.

\section{Materials and methods}

The present randomized controlled trial was approved by the Medical Ethics Committee of the Second Affiliated Hospital of Zhejiang University School of Medicine and informed consent was obtained from all patients.

Study inclusion and exclusion criteria. The inclusion criteria for the present study were as follows: i) Patient was between 18-65 years-old; ii) total burn area $\geq 20 \%$ total body surface area (TBSA) classed as a major burn that requires nutritional therapy (18), of which the deep burn degree II and III area was $\geq 1 \%$ TBSA; iii) the patient was admitted to hospital within 1 week following burn injury; and iv) the patient agreed to participate in the current study. The exclusion criteria were as follows: i) Patient aged $<18$ years or $>65$ years; ii) burn area $<20 \%$ TBSA; iii) superficial second degree burn patients; iv) complicating factors such as unstable glycemic control in diabetic patients, those with malignant tumors, and those with a brain injury; v) pregnancy or lactation; and (5) a life expectancy of $<15$ days. The elimination criteria of patients enrolled on the trial were as follows: i) Those receiving a therapeutic dosage not consistent with that of our study protocol; ii) those not completing a 10 day rhGH treatment.

Patient grouping and treatments. Between February 2009 and November 2011, 63 patients eligible for inclusion in the current study were treated in the Burns Department of the Second Affiliated Hospital of Zhejiang University School of Medicine, Hangzhou, China. Of these, 34 patients were not enrolled, including 19 cases of refusal of patient consent to participate in the research, six patients who did not complete treatment, five cases with life expectancy of $<15$ days, one case with a cerebral vascular accident, and three cases of diabetes with unstable glycemic control. Finally, a total of 29 patients were enrolled in the present study (Fig. 1). All enrolled patients completed the study, without any cases being eliminated following their inclusion. At $\sim 1$ week following burn injury, the patients were

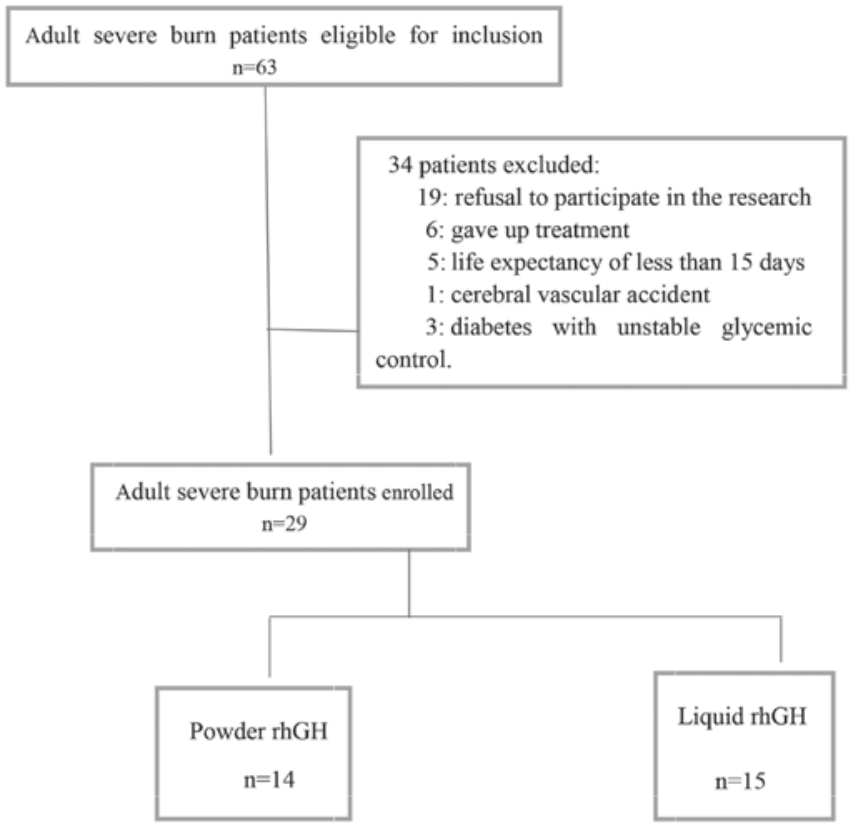

Figure 1. Flow chart of patients enrolled in the study.

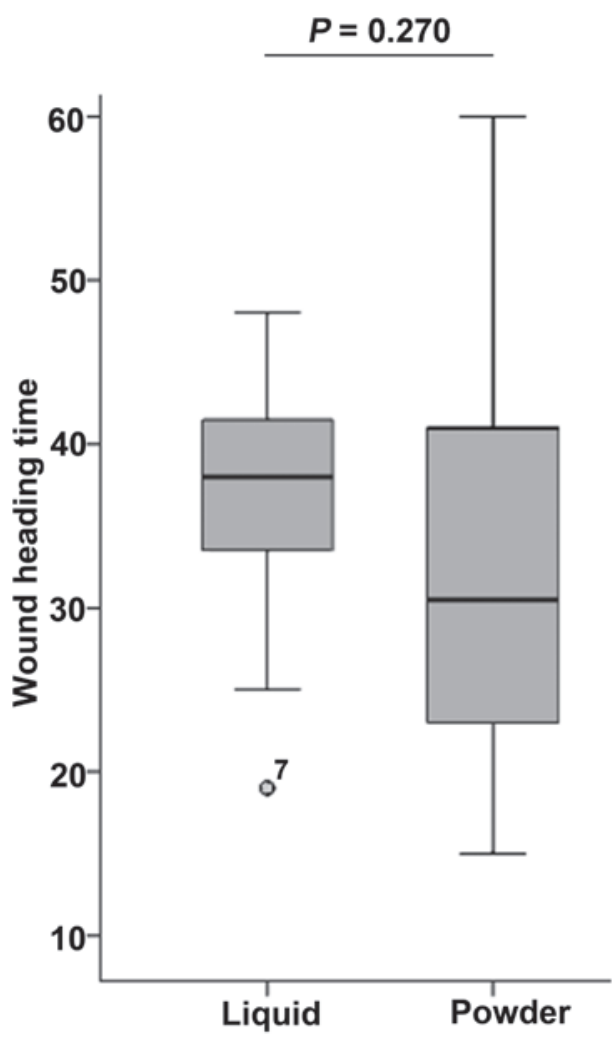

Figure 2. Wound healing time in severe burn patients treated with powdered or liquid forms of $\mathrm{rhGH}$. The data are shown as median (min, max). There was no significant difference between the two groups $(\mathrm{P}=0.270)$.

randomly assigned by block randomization method (with each block containing 4 cases) to either the liquid rhGH group (15 cases) or powder rhGH group (14 cases). We defined burn index (BI) as the sum of full thickness (III degree) burn area, 2/3 deep partial thickness (II degree) burn area and 1/2 superficial partial thickness burn area. 
Table I. Baseline characteristics of severe burn patients treated with powder or liquid forms of rhGH.

\begin{tabular}{|c|c|c|c|}
\hline & Powdered rhGH $(\mathrm{n}=14)$ & Liquid rhGH $(\mathrm{n}=15)$ & P-value \\
\hline Gender (male/female) & $14 / 0$ & $13 / 2$ & 0.480 \\
\hline Age (years) & $42(25-64)$ & $41(20-64)$ & 0.813 \\
\hline Body weight (kg) & $72.25(62.5-89)$ & $69(47-115)$ & 0.046 \\
\hline Deep second degree burn area (TBSA), $\%$ & $9(0-35)$ & $19(1-61)$ & 0.290 \\
\hline Third degree burn area (TBSA), \% & $0(0-32)$ & $3(0-45)$ & 0.377 \\
\hline $\mathrm{BI}$ & $26.7(14.8-56.8)$ & $37.5(12.0-53.3)$ & 0.290 \\
\hline
\end{tabular}

rhGH, recombinant human growth hormone; TBSA, total burn surface area; BI, burn index. Data are presented as median (min, max) or proportion.

The two patient groups were given routine fluid resuscitation, anti-infective treatment, wound management, and nutritional supports. The patients' heat supply was calculated according to the heat supply equation for burns provided by the Third Military Medical University (19). From the 5-7th day after burn injury, rhGH was administered (subcutaneously injected at 7 a.m.) once daily for 10 days. For the liquid rhGH group, liquid rhGH (batch number 081001, 081205, 090702, 20101202 and 20101204; GeneScience Pharmaceuticals Co., Ltd., Changchun, China) was used while for the powder rhGH group, powder rhGH (batch nos. 080902, 081102, 090702, 20100102 and 20100605; Shanghai United Cell Biotechnology Co., Ltd., Shanghai, China) was used. Both groups were the same in the initial timing of drug administration, dosage ( $0.067 \mathrm{mg} / \mathrm{kg} / \mathrm{d}$, depending on the patient's specific conditions) and course of treatment. When the patient's blood glucose level was $>10 \mathrm{mmol} / \mathrm{l}$, a routine dosage of insulin was pumped using micropump to control the blood glucose level under the target of $10 \mathrm{mmol} / \mathrm{l}$.

Observational indexes. At 6 a.m., prior to rhGH injection and on days 3,5 and 10 of rhGH injection, $3 \mathrm{ml}$ fasting venous blood were drawn and sent to the clinical laboratory for examination of pre-albumin (PALB). In addition C-reactive protein (CRP) and fasting blood glucose levels were examined at baseline and on days 5 and 10. PALB and CRP were detected by an AU 5400 chemistry analyzer (Beckman Coulter, Inc., Brea, CA, USA) through immunoturbidimetry.

In the morning, prior to rhGH injection, and on days 5 and 10 of rhGH injection, when the dressings were changed, the patient was weighed without burn dressings and topical treatments. Additionally, the patient's liver and renal functions [alanine aminotransferase (ALT) and blood urea nitrogen (BUN)] were also detected before rhGH injection and on day 10 of rhGH injection. Based on the reference range of our hospital during the testing period, we defined serum ALT $>50 \mathrm{U} / \mathrm{l}$ and $\mathrm{BUN}>7.2 \mathrm{mmol} / \mathrm{l}$ as abnormal.

The wound healing time was recorded as the time from the burn occurrence until the residual burn area $<1 \%$ TBSA or on the 5th day following the last skin graft.

Statistical analysis. All statistical analyses were conducted using SPSS version 17.0 (SPSS Inc., Chicago, IL, USA). The data in the present study were expressed as median (min, max), and compared using Mann-Whitney $U$ test for independent samples. Count data were analyzed by Fisher's exact test. $\mathrm{P}<0.05$ was considered to indicate a statistically significant difference.

\section{Results}

Baseline characteristics. There was no significant difference in the median values of general characteristics such as gender, age, deep II degree burn area, deep III degree burn area and BI between the 15 subjects in the liquid $\mathrm{rhGH}$ and the 14 subjects in the powder rhGH groups (all $\mathrm{P}>0.05$ ), except for body weight $(\mathrm{P}=0.046)$, as shown in Table I.

PALB level. Over the 10 days of observation, PALB levels rose in both groups after treatment, as shown in Table II. Following an initial fall of $3.1(-55.5,60) \mathrm{mg} / \mathrm{l}$ on day 3 in the powder rhGH group compared to an increase of $16.5(-15.9,120) \mathrm{mg} / \mathrm{l}$ in the liquid rhGH group both increased on day 5 by $24.5(-265.4,107.6) \mathrm{mg} / \mathrm{l}$ in the powder $\mathrm{rhGH}$ group and $42.7(-30.6,123.2) \mathrm{mg} / \mathrm{l}$ in the liquid group compared to baseline, and further increased by $65(-259.3,122) \mathrm{mg} / \mathrm{l}$ in the powder rhGH group and $88(-41.7,23.5) \mathrm{mg} / \mathrm{l}$ in the liquid rhGH group. Although the levels were not statistically different between the groups, the differences from baseline were significant on day $10(\mathrm{P}=0.046)$.

CRP, fasting blood glucose level and body weight. The CRP levels fell in both groups after treatment (Table III). However, the levels and the change from baseline did not reveal any significant differences between the groups (all $\mathrm{P}>0.05$ ). The fasting blood glucose levels also fell in both groups following treatment, but not significantly from baseline, nor between groups (all $\mathrm{P}>0.05$; Table III). Body weight was significantly lower in the liquid rhGH group compared to the powder rhGH group before treatment, and on days 5 and $10(\mathrm{P}=0.046$, $\mathrm{P}=0.018$ and $\mathrm{P}=0.006$, respectively). However, the weight change from before treatment was not significantly different between the 2 groups (day 5 difference, $\mathrm{P}=0.591$; day 10 difference, $\mathrm{P}=0.400$; Table III).

Liver and renal function indexes. Among the 15 cases in the liquid rhGH group, there were 7 cases of liver dysfunction prior to treatment and 6 following treatment; by contrast, among the 
14 cases of powder rhGH group, there were 6 cases of liver dysfunction prior to treatment and 7 following treatment as shown in Table IV. The comparison of liver dysfunction between the 2 groups before and after treatment did not demonstrate any significant difference (both $\mathrm{P}>0.05$ ). All 15 cases in the liquid rhGH group had abnormal renal function prior to and following treatment; for the 14 cases in the powder rhGH group, 14 had abnormal renal function prior to treatment and 13 following treatment, as shown in Table IV.

Wound healing time. Would healing time was 38.0 (19.0, $48.0)$ days in the liquid rhGH group and $30.5(15.0,60.0)$ days in the powder rhGH group, without any significant difference observed ( $\mathrm{P}=0.270$ ) (Fig. 2).

\section{Discussion}

Clinically rhGH reduces hypercatabolism following burn injuries, speeding up protein synthesis, improving negative nitrogen balance, promoting burn wound and skin donor site healing, and shortens length of hospital stay, and its wide use in treating burn patients has been commonly recognized by physicians $(12,13)$. Thus, rhGH is one of the options available for treatment of severe burns (20). However, it is unclear which form of rhGH, liquid or powder, has better effects in patients with severe burns. Despite the evidence that confirm the effects of powder rhGH on burned patients (21). Hence the present study evaluated the clinical effects of both liquid and powder forms of rhGH on burned patients who needed nutritional support.

Serum albumin, PALB and transferrin are directly linked to nutritional status and have been regarded as traditional indexes for evaluating nutritional status as well as nutritional therapeutic effects (22). However, these indexes are negatively associated with inflammation and stress level. Albumin has a half-life up to 20 days, but is poorly sensitive for short-term nutritional evaluation and predisposed to exogenous protein input (22). Thus, the present study aimed to observe the short-term effects of rhGH, and albumin was not used as one of evaluation indexes. Instead, PALB with half-life of $48 \mathrm{~h}$ was the main observational index since it is more sensitive to the change of nutritional status (22). Statistically, when comparing between 2 groups, PALB change is more sensitive than the raw data of different points (21). In the present study, liquid rhGH took less time and was better at improving PALB levels compared with powdered rhGH, supporting the suggestion that rehydration of powdered rhGH may risk causing protein aggregation (16), resulting in a lower ratio of biologically active protein than those that have been stored in solution. The two groups were given the same dosage of rhGH calculated according to $\mathrm{mg} / \mathrm{kg} / \mathrm{d}$, however, the liquid $\mathrm{rhGH}$ was actually more potent. In other words, the liquid rhGH was more clinically biologically active and more effective. This may be seen as contradictory to previous studies that found liquid and powdered rhGH to be bioequivalent $(14,15)$. But those studies were more concerned with pharmacokinetics and not the levels of PALB. In addition, since the changes of inflammatory and stress indexes such as CRP and blood glucose levels did not differ significantly between the two groups, the results of the present study suggest that inflammation and stress levels 
Table III. Clinical variables in severe burn patients treated with powder or liquid forms of rhGH.

\begin{tabular}{lccccc}
\hline Variable & Baseline & Day 5 & Day 10 & $\Delta 1$ & $\Delta 2$ \\
\hline CRP $(\mathrm{mg} / \mathrm{l})$ & & & & & \\
Powder rhGH & $133.5(61,175)$ & $103(21.8,217)$ & $57.75(17.9,147)$ & $-46(-88,155.8)$ & $-58.5(-133.7,85.8)$ \\
Liquid rhGH & $156(39,266)$ & $102(5.2,276)$ & $56.5(1.9,217)$ & $-42(-125,21)$ & $-91(-218.6,134)$ \\
P-value $^{a}$ & 0.201 & 0.880 & 0.914 & 0.715 & 0.400 \\
FPG (mmol/l) & & & & & \\
Powder rhGH & $146.5(101,245)$ & $123(67,217)$ & $115(71,228)$ & $-24(-76,44)$ & $-10.5(-137,99)$ \\
Liquid rhGH & $137(81,255)$ & $143(60,312)$ & $110(60,333)$ & $18(-181,151)$ & $-30(-132,194)$ \\
P-value & 0.377 & 0.477 & 0.561 & 0.093 & 0.715 \\
BW (kg) & & & & $-1.25(-7,4)$ & $-2.25(-9,6)$ \\
Powder rhGH & $75.25(63,89)$ & $71.5(59,91)$ & $71.5(61,87)$ & $-3(-10,4.5)$ & $-3.5(-26,4)$ \\
Liquid rhGH $_{\text {P-value }}$ & $69(47,115)$ & $66(51,105.5)$ & $65(48,89)$ & 0.591 & 0.400 \\
\hline
\end{tabular}

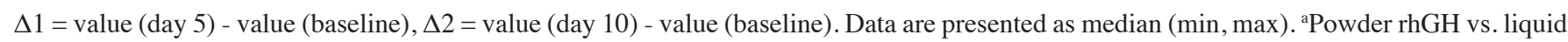
rhGH. CRP, C-reactive protein; FPG, fasting plasma glucose; BW, body weight; rhGH, recombinant human growth hormone.

Table IV. Liver and kidney function in severe burn patients, treated with powdered or liquid forms of rhGH.

\begin{tabular}{|c|c|c|c|c|c|c|}
\hline & \multicolumn{3}{|c|}{ Baseline } & \multicolumn{3}{|c|}{ Day 10} \\
\hline & $\begin{array}{c}\text { Powder rhGH } \\
n=14\end{array}$ & $\begin{array}{l}\text { Liquid rhGH } \\
\qquad n=15\end{array}$ & $\mathrm{P}$-value & $\begin{array}{c}\text { Powder rhGH } \\
n=14\end{array}$ & $\begin{array}{l}\text { Liquid rhGH } \\
n=15\end{array}$ & P-value \\
\hline \multicolumn{7}{|c|}{ Liver function, $\mathrm{n}(\%)$} \\
\hline Normal & $8(53.3)$ & $8(57.1)$ & 1.000 & $7(50.0)$ & $9(60.0)$ & 0.715 \\
\hline Abnormal & $6(46.7)$ & $7(42.9)$ & & $7(50.0)$ & $6(40.0)$ & \\
\hline \multicolumn{7}{|c|}{ Kidney function, n (\%) } \\
\hline Normal & 0 & 0 & - & $1(7.1)$ & 0 & 0.483 \\
\hline Abnormal & $14(100)$ & $15(100)$ & & $13(92.9)$ & $15(100)$ & \\
\hline
\end{tabular}

Serum ALT >50 U/l and BUN >7.2 mmol/1 was defined as abnormal. rhGH, recombinant human growth hormone.

were not different in the two groups and so should not have influenced the detection of PALB.

One factor that may be considered to be less beneficial is the significantly lower total body weight in the patients receiving liquid $\mathrm{rhGH}$; however, this difference was clear before treatment started and the loss in body weight from baseline was not significant between the two groups. As the issue of hypermetabolism lasts several months after the occurrence of the severe burn, overall the body weight measurements would have more value if they were investigated over a longer period of time as rhGH has been shown in children with severe burns to improve growth and body mass in studies that have lasted 12 months $(23,24)$. It would have been interesting to observe any significant difference between the groups after many months.

Theoretically, since liquid rhGH is more spatially stable and biologically active, it should be more effective in promoting wound healing than powdered rhGH. As studies have indicated that rhGH promotes wound healing including speeding up burn wound and skin graft donor/recipient site healing, compared to placebo for the control group $(13,21)$. Nevertheless, the results of the present study showed no significant difference in wound healing time between the two groups, and did not confirm the advantages of rhGH injection in promoting wound healing. This may be due to the small sample size, as both groups were receiving the benefit of rhGH, but if in the case of the powdered form there was slightly less benefit, the differences may have been too small to see in a study of this kind.

The present study has some limitations. A limited number of cases were included, and some of the indexes especially wound healing time were not significantly different between the two groups. After a comprehensive analysis of our data, we primarily draw on the conclusion that rhGH injection is faster acting and more effective in improving the nutritional status of burn patients, but it still should be supported by a large-sample, multicenter clinical trial in the future.

In conclusion, the liquid form of rhGH may be more beneficial to patients with severe burns requiring nutritional support than the powdered form. 


\section{Acknowledgements}

The present study was supported by special clinical research fund of Zhejiang Medical Association (grant no. 2008ZYC13).

\section{References}

1. Palmieri TL, Przkora R, Meyer WJ III and Carrougher GJ: Measuring burn injury outcomes. Surg Clin North Am 94 909-916, 2014.

2. Spanholtz TA, Theodorou P, Amini P and Spilker G: Severe burn injuries: Acute and long-term treatment. Dtsch Arztebl Int 106 607-613, 2009

3. Al-Mousawi AM, Mecott-Rivera GA, Jeschke MG and Herndon DN: Burn teams and burn centers: The importance of a comprehensive team approach to burn care. Clin Plast Surg 36: 547-554, 2009.

4. Williams FN, Herndon DN and Jeschke MG: The hypermetabolic response to burn injury and interventions to modify this response. Clin Plast Surg 36: 583-596, 2009.

5. Atiyeh BS, Gunn SW and Dibo SA: Nutritional and pharmacological modulation of the metabolic response of severely burned patients: Review of the literature (Part II)*. Ann Burns Fire Disasters 21: 119-123, 2008.

6. Rojas Y, Finnerty CC, Radhakrishnan RS and Herndon DN: Burns: An update on current pharmacotherapy. Expert Opin Pharmacother 13: 2485-2494, 2012.

7. Blizzard RM: History of growth hormone therapy. Indian J Pediatr 79: 87-91, 2012

8. Hwang IT: Efficacy and safety of growth hormone treatment for children born small for gestational age. Korean J Pediatr 57: 379-383, 2014.

9. Fukuda I, Hizuka N, Muraoka T and Ichihara A: Adult growth hormone deficiency: Current concepts. Neurol Med Chir (Tokyo) 54: 599-605, 2014.

10. Arce VM, Devesa P and Devesa J: Role of growth hormone (GH) in the treatment on neural diseases: From neuroprotection to neural repair. Neurosci Res 76: 179-186, 2013.

11. Kemp SF and Frindik JP: Emerging options in growth hormone therapy: An update. Drug Des Devel Ther 5: 411-419, 2011.

12. Chen GX and Han CM: Influence of recombinant human growth hormone on the prognosis of patients with severe burns a prospective multi-center clinical trial. Zhonghua Shao Shang Za Zhi 21: 347-9, 2005 (In Chinese).

13. Breederveld RS and Tuinebreijer WE: Recombinant human growth hormone for treating burns and donor sites. Cochrane Database Syst Rev 15: CD008990, 2012.
14. Liedert B, Forssmann U, Wolna P, Golob M and Kovar A: Comparison of the pharmacokinetics, safety and tolerability of two concentrations of a new liquid recombinant human growth hormone formulation versus the freeze-dried formulation. BMC Clin Pharmacol 10: 14, 2010.

15. Fuhr U, Tuculanu D, Berghout A, Balser S, Schwebig A and Saenger P: Bioequivalence between novel ready-to-use liquid formulations of the recombinant human GH Omnitrope and the original lyophilized formulations for reconstitution of Omnitrope and Genotropin. Eur J Endocrinol 162: 1051-1058, 2010.

16. Wiesbauer J, Prassl R and Nidetzky B: Renewal of the air-water interface as a critical system parameter of protein stability: Aggregation of the human growth hormone and its prevention by surface-active compounds. Langmuir 29: 15240-15250, 2013.

17. Iyoda K, Moriwake T, Seino Y and Niimi H: The clinical usefulness of liquid human growth hormone (hGH) (Norditropin SimpleXx in the treatment of GH deficiency. Horm Res 51 (Suppl 3): S113-S115, 1999.

18. Rousseau AF, Losser MR, Ichai C and Berger MM: ESPEN endorsed recommendations: Nutritional therapy in major burns. Clin Nutr 32: 497-502, 2013.

19. Jie W and Wang S: A nutritional formula suitable for adults' burns in China. Chinese Journal of Surgery 5: 262-266, 1992.

20. Gauglitz GG, Williams FN, Herndon DN and Jeschke MG: Burns: Where are we standing with propranolol, oxandrolone, recombinant human growth hormone, and the new incretin analogues? Curr Opin Clin Nutr Metab Care 14: 176-181, 2011.

21. Herndon DN, Barrow RE, Kunkel KR, Broemeling L and Rutan RL: Effects of recombinant human growth hormone on donor-site healing in severely burned children. Ann Surg 212: 424-429; discussion 430-421, 1990.

22. Cynober L: Laboratory measurements in clinical nutrition. In: Basics in clinical nutrition (4th edition). Sobotka L (eds) and Wei C (translator). Shanghai Jiaotong University Press, Shanghai, pp398-402, 2013 (In Chinese).

23. Branski LK, Herndon DN, Barrow RE, Kulp GA, Klein GL, Suman OE, Przkora R, Meyer W III, Huang T, Lee JO, et al: Randomized controlled trial to determine the efficacy of long-term growth hormone treatment in severely burned children. Ann Surg 250: 514-523, 2009.

24. Przkora R, Herndon DN, Suman OE, Jeschke MG, Meyer WJ, Chinkes DL, Mlcak RP, Huang T and Barrow RE: Beneficial effects of extended growth hormone treatment after hospital discharge in pediatric burn patients. Ann Surg 243: 796-801; discussion 801-793, 2006 